\section{Commentary: Another epicardial device for secondary mitral regurgitation: Is this one different?}

\author{
Alexander A. Brescia, MD, MSc, and \\ Steven F. Bolling, MD, on behalf of the Michigan \\ Mitral Research Group (MMRG)
}

Thourani and colleagues ${ }^{1}$ describe a novel, off-pump, epicardial implant intended to reshape the mitral valve and remodel the left ventricle, and they report outcomes after implantation of this device for treatment of secondary mitral regurgitation (MR) in 5 patients undergoing concomitant off-pump coronary artery bypass grafting. The authors should be commended on the first-in-human experience with the Mitral Touch (Mitre Medical Corp, Morgan Hill, Calif) device and implanting it with technical success and favorable outcomes at 1 year.

As many have previously written, preventing residual and recurrent MR is the key to a favorable outcome for both primary and secondary MR. ${ }^{2}$ Secondary MR presents an additional challenge, as it is a disease of the ventricle rather than just the mitral valve alone. Two surgical annuloplasty Cardiothoracic Surgical Trials Network (CTSN) trials ${ }^{3,4}$ and the transcatheter COAPT (Cardiovascular Outcomes Assessment of the MitraClip Percutaneous Therapy for Heart Failure Patients With Functional Mitral Regurgitation) ${ }^{5}$ and MITRA-FR (Multicentre Study of Percutaneous Mitral Valve Repair MitraClip Device in Patients With Severe Secondary Mitral Regurgitation) ${ }^{6}$ MitraClip trials targeted the valve alone to reduce MR, but with mixed results for impacting left ventricular (LV) geometry. A measure of effectiveness of an intervention treating secondary MR is reversing the disease of the ventricle, often measured through cardiac remodeling and LV geometry. As noted by the authors, other epicardial approaches have been

From the Department of Cardiac Surgery, University of Michigan, Ann Arbor, Mich. Disclosures: The authors reported no conflicts of interest.

The Journal policy requires editors and reviewers to disclose conflicts of interest and to decline handling or reviewing manuscripts for which they may have a conflict of interest. The editors and reviewers of this article have no conflicts of interest.

Received for publication Dec 24, 2020; revisions received Dec 24, 2020; accepted for publication Dec 28, 2020; available ahead of print Jan 8, 2021.

Address for reprints: Alexander A. Brescia, MD, MSc, Department of Cardiac Surgery, University of Michigan, Frankel Cardiovascular Center, 1500 E Medical Center Dr, Ann Arbor, MI 48109 (E-mail: abrescia@med.umich.edu).

J Thorac Cardiovasc Surg 2023;165:e152-3

$0022-5223 / \$ 36.00$

Copyright (c) 2021 by The American Association for Thoracic Surgery

https://doi.org/10.1016/j.jtcvs.2020.12.127

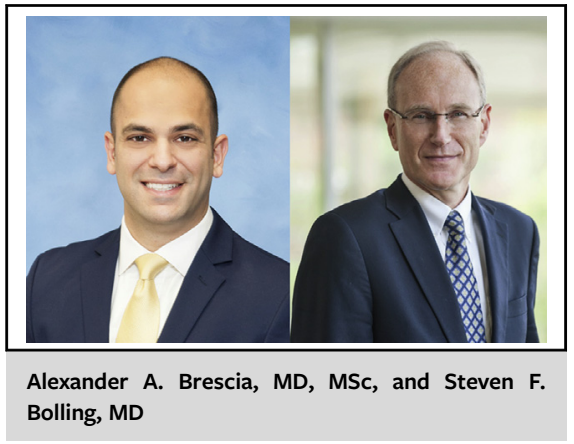

CENTRAL MESSAGE

A novel, off-pump, epicardial

implant for treating secondary

mitral regurgitation and

improving ventricular remodel-

ing is demonstrated. However, applicability and clinical adoption

remain to be seen.

previously described, including suture and mesh, ${ }^{7}$ the Acorn epicardial wrap, ${ }^{8}$ and the LV reshaping Coapsys device (Myocor, Inc, Maple Grove, Minn) in the RESTORMV (Randomized Evaluation of a Surgical Treatment for Off-Pump Repair of the Mitral Valve) trial. ${ }^{9}$ The ACORN $^{8}$ and RESTOR-MV ${ }^{9}$ trials demonstrated improved LV geometry, but no epicardial surgical technique has been widely adopted. Unlike other surgical and transcatheter devices addressing MR alone, the Mitral Touch is the latest example of an epicardial device that addresses both the secondary MR and the underlying diseased ventricle.

Previous epicardial devices ${ }^{7-9}$ did not gain wide acceptance because of the invasiveness required to use them. Similarly, implantation of the Mitral Touch device is not without morbidity and still requires that surgery be performed through a sternotomy. However, the device is intended for off-pump use, avoids an atriotomy, and in this feasibility study was used concomitant to off-pump coronary artery bypass grafting. For various geometric reasons, only 5 of the 11 screened patients underwent device implantation, which may predict a narrow applicability. As additional feasibility trials continue in the United States, it will be important to characterize what proportion of patients with severe secondary MR may benefit from this device. 
In conclusion, the authors should be commended for a successful initial feasibility report of the Mitral Touch device. As investigations continue, a solution with more widespread application in a broader population may involve addressing both secondary MR and the diseased ventricle to promote $\mathrm{LV}$ remodeling through a transcatheter/percutaneously-delivered device that can achieve a comparable impact while avoiding open surgery entirely.

\section{References}

1. Thourani VH, George I, Rucinskas K, Kalinauskas G, Janusauskas V, Zakarkaite D, et al. First in human experience with an epicardial beating heart device for secondary mitral regurgitation. J Thorac Cardiovasc Surg. 2021;161: 949-58.e4.

2. Brescia AA, Bolling SF, Michigan Mitral Research Group (MMRG). Commentary: MR is bad! J Thorac Cardiovasc Surg. May 30, 2020 [Epub ahead of print].
3. Goldstein D, Moskowitz AJ, Gelijns AC, Ailawadi G, Parides MK, Perrault LP, et al. Two-year outcomes of surgical treatment of severe ischemic mitral regurgitation. N Engl J Med. 2016;374:344-53.

4. Michler R, Smith P, Parides M, Ailawadi G, Thourani V, Moskowitz A, et al. Twoyear outcomes of surgical treatment of moderate ischemic mitral regurgitation. N Engl J Med. 2016:374:1932-41.

5. Stone GW, Lindenfeld J, Abraham WT, Kar S, Lim DS, Mishell JM, et al. Trans catheter mitral-valve repair in patients with heart failure. N Engl J Med. 2018;379: 2307-18.

6. Obadia J-F, Messika-Zeitoun D, Leurent G, Iung B, Bonnet G, Piriou N, et al. Percutaneous repair or medical treatment for secondary mitral regurgitation. $N$ Engl J Med. 2018;379:2297-306.

7. Raman J, Hare D, Storer M, Hata M. Epicardial cardiac basal annuloplasty: preliminary findings on extra-cardiac mitral valve repair. Heart Lung Circ. 2009; 18:401-6.

8. Ali MW, Bolling SF. Mitral valve repair: what the ACORN trial taught us. Curr Cardiol Rep. 2010;12:116-21.

9. Grossi EA, Patel N, Woo YJ, Goldberg JD, Schwartz CF, Subramanian V, et al Outcomes of the RESTOR-MV trial (randomized evaluation of a surgical treatment for off-pump repair of the mitral valve). J Am Coll Cardiol. 2010;56: 1984-93.

\section{Commentary: Old problem, new solution: Epicardial annuloplasty with left ventricular support for functional mitral regurgitation}

\author{
Edward G. Soltesz, MD, MPH
}

Functional mitral regurgitation (FMR) remains a challenging problem for surgeons. The optimal surgical treatment is still a matter of significant debate. Over the last decade, surgeons have come to appreciate the pathophysiology of this disease process as a complex interplay

\footnotetext{
From the Department of Thoracic and Cardiovascular Surgery and Kaufman Center for Heart Failure and Recovery, Heart and Vascular Institute, Cleveland Clinic, Cleveland, Ohio.

Disclosures: Dr Soltesz reports consulting for Abbott, Abiomed, and AtriCure.

The Journal policy requires editors and reviewers to disclose conflicts of interest and to decline handling or reviewing manuscripts for which they may have a conflict of interest. The editors and reviewers of this article have no conflicts of interest.

Received for publication Dec 26, 2020; revisions received Dec 26, 2020; accepted for publication Dec 28, 2020; available ahead of print Jan 8, 2021.

Address for reprints: Edward G. Soltesz, MD, MPH, Department of Thoracic and Cardiovascular Surgery, Cleveland Clinic, 9500 Euclid Ave Desk J4-1, Cleveland, OH 44195 (E-mail: soltese@ccf.org).

J Thorac Cardiovasc Surg 2023;165:e153-4

$0022-5223 / \$ 36.00$

Copyright (c) 2021 by The American Association for Thoracic Surgery

https://doi.org/10.1016/j.jtcvs.2020.12.125
}

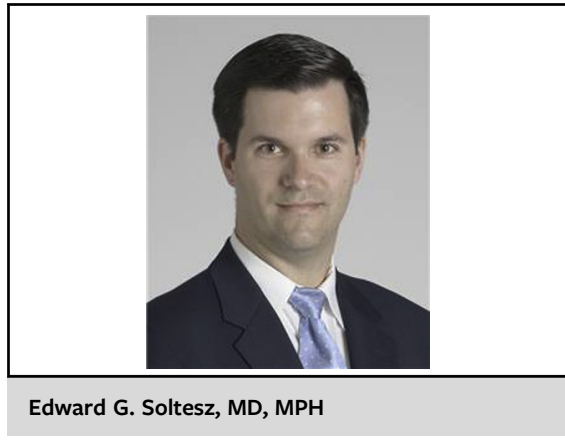

CENTRAL MESSAGE

The Mitral Touch annuloplasty device deserves attention as a possible solution to the problem of functional mitral regurgitation through combined annular reshaping and left ventricular support.

between the mitral valve, including its subannular structures, and the left ventricle. In addition, recent surgical and transcatheter trials and subsequent post hoc analyses have suggested that there are in fact multiple phenotypes of FMR (ie, proportionate vs disproportionate) that respond differently to intervention directed at various components of the mitral-ventricular complex. ${ }^{1-3}$ Unfortunately, many 